\title{
EDITORIAL
}

\section{UMA ABORDAGEM FILOSÓFICA DO DIREITO}

Robison Tramontina Prof. Dr. PPGD | Unoesc Editor Assistente da EJJL

A realização e a efetivação dos Direitos Fundamentais exigem investigações e reflexões teóricas consistentes e adequadas sobre os mesmos e os possíveis mecanismos para garanti-los. Caso seja correto que não há teoria sem prática, também sem boa teoria diminui a possibilidade de se conceber boas práticas.

Inspirados por essa máxima, entende-se que uma abordagem filosófica do direito possibilita uma visão apropriada e profunda do direito como um todo. Explicitar sumariamente essa noção é propósito desta intervenção.

A filosofia do direito ${ }^{1}$, o próprio nome sugere, pode ser entendida como uma abordagem filosófica do direito. Nessa noção estão pressupostas duas outras: as noções de filosofia e a de direito. Nesse sentido, como já observou Alexy (1994), a própria filosofia do direito não pode ser definida sem usar o conceito de direito que ela tem como tarefa explicitar. No entanto, tendo em vista a necessidade de se dispor desde o inicio de tais conceitos, pode-se partir da pré-compreensão dos mesmos já disponível na linguagem ordinária.

Assim, pode-se aceitar sem maiores detalhamentos a ideia de que a filosofia do direito é uma abordagem filosófica sobre os seguintes conceitos: direito, ter um direito, justiça, moral, legitimidade, positivismo, direitos humanos, direitos básicos, norma fundamental, validade, eficácia, vigência, lacunas e outros (DUTRA,2008).

Os temas que a filosofia do direito aborda parecem ser os mesmos que são tratados em outras disciplinas, como por exemplo, sociologia do direito ou teoria do direito (TGD). O que a diferencia das disciplinas mencionadas?

A sociologia do direito preocupa-se com o caráter eficaz e coercitivo do direito, como o direito se realiza/efetiva na sociedade. É uma abordagem empírica. A teoria do direito se nutre do próprio direito enquanto ordenamento positivado, busca construir, a partir dos fragmentos da legislação e da doutrina, um sistema coerente. A teoria jurídica mergulha no ordenamento jurídico e se fecha a qualquer exterioridade (DUTRA, 2008).

Caso a descrição da sociologia jurídica e da teoria do direito estejam corretas, pode-se afirmar que a filosofia do direito, por não ser empírica e aberta, trata o fenômeno jurídico de maneira distinta. Podem existir divergências quanto ao que seja a filosofia, mas certamente ela não é ciência, nem dogmática.

$\overline{1}$ Não há acordos entre os autores sobre o que é a filosofia do direito. Contudo, é necessário ter uma noção do que ela seja. 
Após uma breve apresentação acerca da uma noção possível de filosofia do direito, destaca-se a finalidade dela. Pode se atribuir à filosofia do direito pelos menos, duas funções: a) estimular a reflexão e b) fazer uma crítica do conhecimento jurídico imposto pela doutrina. Trata-se de uma divisão meramente didática, pois, na verdade, há uma interdependência dessas metas, ou seja, quando se estimula o pensamento daquele que trabalha com o Direito de forma eficaz promove-se, concomitantemente, uma crítica do conhecimento jurídico proposto pela doutrina.

Essa afirmação sugere o conceito e papel para a Filosofia do Direito: instigar a capacidade reflexiva do profissional do Direito oferecendo-lhe condições (métodos) e oportunidades para pensar criticamente o Direito.

Para Reale (2002, p.10), é da natureza do filósofo do Direito converter "em problema o que para o jurista vale como resposta ou ponto assente e imperativo". Essa afirmação oferece indicação acerca de uma das finalidades da Filosofia do Direito: problematizar.

Mas, o que significa problematizar? De acordo com Gabriel (2015):

Problematizar é o ato de transformar em questionamento algo tido como seguro e resolvido. [...] É a habilidade de transformar em uma pergunta bem elaborada as indagações que perturbam as pessoas. É, enfim, colocar um ponto de interrogação inesperado onde já descansa tranquilo e satisfeito um ponto final.

Até agora destacou-se que a filosofia do direito estimula o pensamento (reflexão) e a problematização sobre o direito.

Porém, além disso, a filosofia do direito também tem uma finalidade prática/pragmática. O profissional do Direito que conhece sobre Filosofia do Direito, e que é capaz de filosofar sobre o fenômeno jurídico, consegue extrair bons frutos dessa prática, entre os quais, a criatividade e a capacidade crítica. Cretella Júnior é bastante enfático a respeito dessa possibilidade: "Na verdade, pode-se advogar mediocremente (e até razoavelmente) sem conhecer Filosofia do Direito, mas não pode haver jamais um expoente, na arte de advogar, que não conheça Lógica, Filosofia e Filosofia do Direito, porque é impossível versar sobre grandes questões do Direito com o emprego tão-só da técnica de advogar (1993, p. 7)".

Como já destacado acima, a filosofia do direito pode ser entendida como uma abordagem filosófica sobre o direito. Essa noção informa, mas não esclarece de maneira clara e suficiente, o que é a área do conhecimento que se quer explicitar.

Para se ter uma noção mais clara da filosofia do direito é necessário esclarecer as características da abordagem filosófica, faz-se necessário compreender o que significa abordar filosoficamente algo/ alguma coisa.

Uma observação importante, da descrição do que é e como se faz filosofia, é possível se chegar à noção de abordagem filosófica, ou seja, para esclarecer o que significa a abordagem filosófica é necessário destacar-se uma ideia do que é a filosofia.

Não há uma resposta única para tal questão, uma vez que há divergências entre os autores sobre o que é a filosofia e sua forma de abordar os problemas. Contudo, é necessário enfrentar a 
questão. E para se atingir o propósito estabelecido, serão pinçados da literatura especializada alguns entendimentos. De acordo com Warburton (1998, p. 20):

A filosofia é uma atividade, é uma forma de pensar acerca de certas questões. A sua característica mais marcante é o uso de argumentos lógicos. A atividade dos filósofos é, tipicamente, argumentativa: ou inventam argumentos, ou criticam os argumentos de outras pessoas ou fazem as duas coisas. Os filósofos também analisam e clarificam conceitos. [...]

Que tipo de coisas discutem os filósofos desta tradição? [ocidental] Muitas vezes, examinam crenças que quase toda a gente aceita acriticamente a maior parte do tempo. Ocupam-se de questões relacionadas com o que podemos chamar vagamente "o sentido da vida": questões acerca da religião, do bem e do mal, da política, da natureza do mundo exterior, da mente, da ciência, da arte e de muitos outros assuntos. Por exemplo, muitas pessoas vivem as suas vidas sem questionarem as suas crenças fundamentais, tais como a crença de que não se deve matar. Mas por que razão não se deve matar? Que justificação existe para dizer que não se deve matar? Não se deve matar em nenhuma circunstância? E, afinal, que quer dizer a palavra "dever"? Estas são questões filosóficas. Ao examinarmos as nossas crenças, muitas delas revelam fundamentos firmes; mas algumas não. $\mathrm{O}$ estudo da filosofia não só nos ajuda a pensar claramente sobre os nossos preconceitos, como ajuda a clarificar de forma precisa aquilo em que acreditamos. Ao longo desse processo desenvolve-se uma capacidade para argumentar de forma coerente sobre um vasto leque de temas - uma capacidade muito útil que pode ser aplicada em muitas áreas.

Pode-se inferir, seguindo a caracterização dada pelo autor, que:

a) A filosofia é uma forma de pensar sobre certo tipo de questões2;

b) A filosofia é atividade argumentativa - trabalha com argumentos;

c) A filosofia opera/trabalha com problemas.

Para aprofundar um pouco mais essa ideia, menciona-se Murcho (2015). De acordo com ele, a filosofia não tem características especificas, mas alguns traços que auxiliam na tentativa inicial de compreender a atividade filosófica, são eles:
a) É uma atividade crítica;
b) O pensamento filosófico é consequente;
c) A filosofia é um estudo conceitual;
d) A filosofia é diferente da história da filosofia.

\footnotetext{
2 Outros problemas/questões que os filósofos se ocupam: Qual é a natureza da filosofia? Há problemas filosóficos?; Qual é o método correto para resolver problemas filosóficos? Quando temos boas inferências? Qual é a natureza da racionalidade? $\bigcirc$ que é a verdade? $\bigcirc$ que é conhecer algo? $\bigcirc$ que percepcionamos quando afirmamos percepcionar o mundo? Podemos saber que o mundo exterior existe? $O$ que é a realidade? Em que consiste algo existir? Que gêneros de coisas existem? O que é uma causa? Em que consiste algo ser moralmente bom? O que é a vida boa? É possível se justificar os juízos éticos? Qual é a natureza da mente? O que é a consciência? O que é o eu? O que é isso de as expressões de uma língua terem significado? O que é compreender o significado de uma palavra? O que justifica o poder do estado? O que são os direitos humanos?

Poderemos justificar as avaliações que fazemos das obras de arte? O que determina o significado de uma obra de arte? Em que consiste justificar a existência de Deus? Qual é a natureza de Deus? Como devemos viver?
} 
a) A filosofia é de o lugar crítico da razão. Seu objetivo é avaliar criticamente certo tipo de ideias. Existem teorias, teses, ideias dos filósofos que precisam ser discutidas.

b) Um dos objetivos da filosofia como disciplina é estimular cada qual pensar por si. Sendo assim, alguns acadêmicos imaginam erradamente que a filosofia é o domínio da arbitrariedade e do "vale tudo". Pensam que qualquer frase absurda e sem sentido é filosofia ou que pode afirmar o que quiser. No entanto, ela não uma é coletânea de bizarrices e esquisitices, mas uma tentativa de fundamentação racional das nossas ideias. Por isso, o pensamento filosófico é consequente.

c) A filosofia é um estudo conceitual. Os problemas abordados pela filosofia requerem pouca informação empírica. Por exemplo, para saber se os animais têm direitos é relevante ter dados biológicos sobre a questão de saber se eles sentem dor — mas esses dados o filósofo vai procurá-los na biologia, dado que isso não é um trabalho da filosofia. O que o filósofo faz é refletir sobre o significado filosófico desses dados.

d) Qualquer problema filosófico precisa ser discutido levando em conta os que os filósofos disseram. Mas daí não se segue que a filosofia se reduza a fazer relatórios e interpretações das ideias dos filósofos anteriores a nós. Isso é o que faz a história da filosofia. Em filosofia, esse trabalho é feito com um objetivo: discutir essas ideias, para saber se tais ideias são verdadeiras ou não, quais são os seus pontos fortes e os seus pontos fracos.

Embora a abordagem seja panorâmica, acredita-se que a partir das posições de Warburton (1998) e Murcho (2015) é possível se ter uma visão adequada e razoável dos elementos centrais da abordagem filosófica.

Assim, pode-se defende que a filosofia do direito é espécie do gênero filosofia, e, portanto, caracteriza-se por ser uma forma consequente de pensar conceitual, critica e argumentativamente certos tipo de questões proposta no e pelo direito.

O presente número da EJJL, na maior parte dos seus artigos, destaca um conjunto de reflexões teóricas sobre os direitos humanos e os direitos fundamentais. Em visto disso, este número abre com a entrevista de um dos mais importantes teóricos do direito brasileiro, o Professor Doutor Lenio Streck. A entrevista foi organizada e coordenada pelos Professores Vinicius Mozetic (UNOESC) e Yuri Schneider (PPGD-UNOESC). As questões para o Entrevistado foram formuladas pelos seguintes Professores: Alexandre Morais da Rosa (UFSC/UNIVALLI), Alfonso de Julios-Campuzano (SEVILLA-ESP), Ernildo Stein (PUC-RS), Jorge Miranda (LISBOA-POR), Nuria Belloso Martín (BURGOS-ESP), Rafael Tomaz de Oliveira (UNAERP/SP), Vinicius Mozetic (UNOESC) e Yuri Schneider (UNOESC).

Além da entrevista, mais quatorze (14) artigos redigidos em português, inglês e espanhol compõe o presente número. As contribuições são de autoria de pesquisadores de instituições nacionais e internacionais. 
A Teoria jurídica-filosófica de Robert Alexy é apresentada, sob perspectivas diferentes, em três artigos, a saber: no texto da Prof. Fernando Leal (FGV-RIO), o qual aborda os significados e as controvérsias do princípio da otimização, na investigação da Profa. Carinna Gonçalves Simplício (UNIFEMM - PUC/MG), que aplica a fórmula do peso completa refinada para resolver um caso envolvendo o uso de recursos hídricos em Minas Gerais e o texto dos pesquisadores Mônia Clarissa Hennig Leal (UNISC) e Fernando Roberto Schnorr Alves (UNISC), no qual os autores a partir da teoria do discurso alexiana defendem que a razoabilidade e a teoria da reserva do possível são os fundamentos de um adequado controle judicial de políticas públicas.

Entre as principais questões da jusfilosofia está a discussão acerca da relação existente entre direito e moral. Os Professores Anselmo Laghi Laranja (FDV-ES - TJ-ES) e João Maurício Adeodato (UFPE - FDV-ES) discutem a partir da teoria sistêmica de Niklas Luhmann essa controversa e problemática conexão.

Em se tratando de reflexões de natureza filosófica alguns temas são incontornáveis. Entre eles estão o conceito de dignidade humana e os fundamentos filosóficos dos direitos humanos na sociedade contemporânea. Três textos tematizam ou tangenciam tais questões. Antonio Pele (PUC-RIO) analisa em original e instigante perspectiva a concepção kantiana de dignidade humana. $\bigcirc$ tema da fundamentação intercultural dos direitos humanos é objeto de analise do trabalho apresentado pelos Professores José Querino Tavares Neto (UFG - PUC/PR) e Andrea Abrahão Costa (PUC/PR).

Ainda na seara das considerações teóricas, Fábio Portela Almeida (TST) analisa a importante e conhecida obra "The cost of rights: why liberty depends on taxes" de Cass Sunstein e Stephen Holmes.

Sendo que as discussões sobre direitos humanos e fundamentais não devem e nem podem ficar restritas ao âmbito teórico -filosófico também são necessárias algumas investigações prático-dogmáticas. Neste sentido, sete artigos são apresentados. Dois tratam do tema da seguridade social, uma contribuição vem da Republica Tcheca, a outra do Chile. O Professor Martin Stefko (Charles University) discute a questão da Seguridade Social na União Europeia sob a perspectiva dos trabalhadores migrantes. O Prof. Ivan Obando Camino (TALCA-Chile) analisa o sistema de seguridade social chileno a luz do direito internacional da pessoa humana.

Três investigações tratam de direitos fundamentais civis. Angelo Gamba Prata de Carvalho (UNB) e Claudia Rosane Roesler (UNB) analisam, a partir da teoria da argumentação, as decisões do Supremo Tribunal Federal dos crimes de subversão sob o regime de exceção. Ingo W. Sarlet (PUC-RS) e Amanda Costa Thomé Travincas (PUC-RS/ UNDB/ São Luís-MA) estudam o âmbito de proteção do direito fundamental à liberdade acadêmica. $\bigcirc$ tema da exploração de informações genéticas de povos indígenas é explorado pelas Professoras Christine Noiville (SORBONNE-PARIS1), Florence Bellivier (PARIS OUEST-NANTERRE) e Rosalice Fidalgo Pinheiro (UNIBRASIL).

Os outros dois estudos são "Leading cases". Neles dois casos significativos vinculados a violações de direitos humanos são analisados. Thiago Luís Santos Sombra (UnB) avalia a impactante e relevante ADPF 347 a qual versa sobre "o estado de coisas inconstitucional" do sistema prisional brasileiro. Gizela Iensue (UFMS) discute a possibilidade de se responsabilizar o superior nos casos de 
omissão do mesmo para impedir condutas penais dos subordinados. Tal tema é analisado a luz do caso Jean-Pierre Bemba Gombo.

O presente número da EJJL foi preparado com esmero e cuidado. Faço votos que a leitura seja útil e produtiva.

\section{Referências}

ALEXY, Robert. El concepto y la validez del derecho. Barcelona: Gedisa, 1994.

CRETELLA JUNIOR, José. Curso de filosofia do direito. 11. ed. Rio de Janeiro: Forense, 2007.

DUTRA, Delamar. Manual de Filosofia do direito. Caxias do Sul: UCS, 2008.

GABRIEL, José Luciano. Finalidades da filosofia do direito. Disponível em $<$ http://www.ambito-juridico.com.br/site/index.php?n_link=revista_artigos_leitura\&artigo_id $=11700>$ Acesso em: 22/01/2015.

MURCHO, Desidério. A especificidade da filosofia. Disponível em < http://criticanarede.com/ fil_especificidade.html> Acesso em: 23/01/2015.

REALE, Miguel. Filosofia do direito. 20. ed. São Paulo: Saraiva, 2002.

WARBURTON, Nigel. Elementos básicos de filosofia. Lisboa: Gradiva, 1998. 